ANDRZEJ PAWELEC

Jagiellonian University in Kraków

andrzej.pawelec@uj.edu.pl

\title{
CHANGING THE PLAYING FIELD: A "SOCIAL TURN" IN THE STUDY OF LANGUAGE?
}

Keywords: human linguistic capacity, language as social technology, instruction of imagination, Daniel Dor, Charles Taylor

\begin{abstract}
I would like to suggest that the cognitive perspective on language, developed for over half a century, has been challenged in an unparalleled manner by Daniel Dor (2015). He points out that competing schools of linguistics (formalists, functionalists, pragmaticists) all share Chomsky's original assumption that linguistics is part of Cognitive Science and language is primarily a mental entity. Dor proposes to rethink the status quo in linguistics from an alternative starting point: language is a social communication technology for the instruction of imagination. I believe that this confrontation with mentalism in language study may lead, in time, to a paradigm shift. I also point out - in the context of Charles Taylor's latest (2016) book - that Dor's social perspective on language has its limitations too.
\end{abstract}

The somewhat grandiose formulation of the title is occasioned by a recent publication of two important books on language which openly advertise their great ambitions: Daniel Dor's The instruction of imagination: Language as a social communication technology (2015) and Charles Taylor's The language animal. The full shape of the human linguistic capacity (2016). Taylor - in an adversarial manner - promises a "full" account of linguistic capacity as an antidote to reductive accounts developed within Analytical Philosophy. Dor (2015: 1) calmly declares in the first sentence of his work: "This book attempts to tackle the fundamental question of the linguistic sciences: what is language?" Even though both authors have very different backgrounds and, prima facie, opposing agendas, I would like to argue that their contributions to the study of language are on one level - convergent. I also hope that they will pave the way for a paradigm-change. 
Charles Taylor does not require any introductions. In his long and productive philosophical career he has often published on language (1985, 1995, 2006, 2011, 2016), developing the insights of the Romantic tradition he dubbed "HHH" (Hamann, Herder, Humboldt), while criticizing the reductive accounts of language offered by the Enlightenment "HLC" tradition (Hobbes, Locke, Condillac). His basic claim, embedded in the Continental Philosophy of Language (Heidegger, Gadamer, Merleau-Ponty, Ricoeur), emphasizes the constitutive role of language in the development of humanity: language must not be reduced to a tool for information encoding - it makes possible the truly human life. Taylor's latest book collects much of his previous work and weaves it together into an impressive statement - to be supplemented with a companion volume on the post-Romantic poetics (as a way to reconnect with what makes life meaningful). I will not focus primarily on this attempt as it has been extensively reviewed (most recently by Stalmaszczyk 2016) and I have already presented an assessment of Taylor's general position elsewhere (Pawelec 2009). I would like to invoke Taylor as a backdrop to discuss the limitations of Dor's project.

Daniel Dor is a linguist who has been known so far for his work on the evolution of language within the "evo-devo" paradigm (with Eva Jablonka) and for his critical analysis of the Israeli coverage of Intifada. The present book is a long-term project stemming from his dissatisfaction with the current fragmentation of linguistics. Dor points out that even though competing schools (formalists, functionalists, pragmaticists) pursue different agendas, they share Chomsky's original assumption that linguistics is part of Cognitive Science and language is primarily a mental entity. Dor proposes to rethink the status quo in linguistics from an alternative starting point: language is a social communication technology for the instruction of imagination.

Dor's (2015:1) perspective on language is not new, as he himself points out at the very beginning of his book:

The understanding of language that I wish to offer in these pages begins with a return to a long tradition of thought - a tradition that was expelled from the linguistic sciences by the cognitive revolution, fifty years ago, and is now being locally reconsidered in certain quarters of the field: the human condition is deeply social, and language is a social entity. It is a property of the community, of the social network, the product of a collective process of invention and development. It resides between speakers, not in them, at a level of organization and complexity that transcends the individual mind - and cannot be reduced to it. The place to look at for the essence of language is not the mind-brain. It is social life.

This sketchy characterization rings true to many, I believe, and could perhaps be filled out with some names. The social nature of language was still clearly highlighted by Saussure's notion of langue in his Cours (1959 [1916]), while Wittgenstein's notion of "language games" (1978 [1953]) put paid to the idea of an internal "private" language. Language acquisition as a necessary social prop for the development of conceptual thought was studied by Vygotsky (1962 [1934]) and by - unjustly forgotten - Heinz 
Werner (cf. Werner, Kaplan 1963). One may also mention the long tradition of Anthropological Linguistics (cf. Malinowski 1923) which has invariably underlined social aspects of language (even in its cognitivist phase). What is more, the cognitive revolutions in linguistics (both in the formalist and functionalist guises) have been consistently criticized by scholars from various traditions (recently, for instance, Leezenberg 2001 and Everett 2012).

Dor's initial assumptions are not new, either. The first one states that experience is private - there is no direct access to other minds. This idea has been debated as "the problem of other minds" in Analytical Philosophy. In a more general form concerning the "bridge" between consciousness and reality - it has shaped much of modern philosophy after Descartes. Significantly from our perspective, the attempts to overcome dualisms (subject/ object, mind/matter) have motivated the development of phenomenology and hermeneutics. We are clearly in deep philosophical waters here - navigated by Taylor but left aside by Dor. Still, Dor does mention that the current ideas of "embodied", "situated" and "distributed" cognition point to intersubjective foundations of experience and thus make his assumption look "reactionary". He proposes to adopt it as a "definitional move" to help the reader imagine a world yet unmediated by language (Dor 2015: 17), a solipsistic or minimally intersubjective one, and then also to highlight the fact that even intersubjective experience is egocentric - it is experienced from an individual vantage point. In short, "we are separated from each other by experiential gaps" (Dor 2015: 19).

Dor's second assumption is about the difference between experiential and linguistic communication. The former shares (some of) the features of experience in general, which is "analogue, holistic, fuzzy, and context-dependent" (Dor 2015: 19). Experiential communication is "presentational:" the communicative intention is made visible with gestures (Dor 2015: 24). Dor includes in this category both animal and human actions, say threatening gestures of males on the one hand and pointing or pantomime on the other hand (as far as we know, the latter activities are available only to humans). There is also "re-presentational" communication - achieved by iconic technologies: drawings, maps, musical recording, photographs and films which is quasi-experiential and uniquely human:

[T] he communicator's experiential intent is recorded, frozen in time, delivered from the here-and-now of the communicator's experience into the here-and-now of the receiver, where it is "melted back," so to speak, brought back to life for the receiver to perceive. Much of the original complexity of the experiential intent is lost in the process. No system of re-presentational communication is ever capable of bringing the entire original experience into the present [...]. Just like presentational systems, re-presentational systems do not attempt to bridge the experiential gap between the sender and the receiver: they use various technical means to allow for the sharing of experience across time and space, without actually bridging the gap (Dor 2015: 24).

Linguistic communication takes a different course: it does not attempt to present private experience by some perceptible means but rather offers an instruction, an ordered list of general coordinates of the experience in question on the basis of which 
(and one's own prior experience) the receiver is expected to imagine what has been communicated (Dor 2015: 24-25). As opposed to experiential communication, language is digital: it works not with analogue icons of experience but with differential symbols which communicate stereotyped entities, types of experience.

The target of Dor's account is clear when we recall, for instance, Pinker's (1994: 15) description of language:

As you are reading these words, you are taking part in one of the wonders of the natural world. For you and I belong to a species with a remarkable ability: we can shape events in each other's brains with exquisite precision [...]. That ability is language. Simply by making noises with our mouths, we can reliably cause precise new combinations of ideas to arise in each other's minds.

Language, pace Pinker, is not a tool for the transmission of ideas from one mind to another. This "language myth" (based on the myths of fixed-code and telementation) has been tirelessly exposed by Roy Harris and his "integrationist" school in numerous publications (see, for instance, Harris, Wolf 1998). Dor (2015: 50) shows why there is no "telementation": linguistic "expression" converts a private, analogue meaning of a speaker into a collective, digital meaning - a set of abstract, stereotypical directives - to be converted back (or reconstructed) by an interlocutor on the basis of his own experience. Thus, private messages are not sent via "a conduit" (cf. Reddy 1979, an important reference for Dor) but they are shaped in a social medium as prompts to be given experiential meaning again by the interlocutor. Dor sketches this process of "production and comprehension" in Chapter 6 of his book. His preliminary account, I believe, could be usefully compared with McNeill's (2005, section 2.4) "imagery-language dialectic", which offers a more specific and dynamic description, involving gestures (paralanguage).

What is necessary to make this technology work? Dor (2015: 25) mentions two elements: "the symbolic landscape, a collectively coded model of the world, and the communication protocol - a set of normative rules for the regulation of instructive communication". The rest of the book is a development and an application of this perspective to various fields of language study. As pointed out in an exhaustive and highly competent review of this work:

Dor fundamentally turns nearly every basic assumption in contemporary linguistic theory on its head [...]. At the very least, [his] fundamental criticism of contemporary linguistics theories deserves a considered response from each of the frameworks implicated, particularly those in the cognitive-functional realm. At best, [the book] lays the foundation for a realistic and socially based reconceptualization of linguistic theory (Spronck 2016a; cf. a shortened version: Spronck 2016b).

I share Spronck's positive assessment of Dor's project and hope for its widespread impact: confronting mentalistic ontology of language with a credible social alternative has been long overdue and we are all indebted to Dor for his attempt. It seems, however, that the very effort to distance himself from established positions sometimes leads Dor to underestimate their value. This may be the case with Construction 
Grammar, as pointed out by Spronck (2016b: 3). I also believe that Dor's critique of functionalism relies on an undervaluation of the central concept of "motivation" which any realistic theory of language requires. The question to ask is: why some form is accepted as the vehicle of a specific meaning?

Dor points out, in reference to different types of iconicity, that such external motivations are variable and in competition, hence structural variability merely reflects an underlying variability of experience; consequently, if some forms (structural regularities) occur, this is due (in the final account) to "emergent patterns of prescriptive order" (Dor 2015: 155). He even offers a scenario in which:

some innovative individuals realized, at certain points in the languages' evolution, that communication would become more effective if speakers could be made to arrange the elements of their utterances in ways that reflect something of the order of their experiences. These innovative individuals were probably more sensitive to iconicity than others, and they were probably more attuned to the problems of unorderly communication: they may have experienced more difficulty than the others in understanding what was being said, and they may have found themselves looking for ways to express something about the internal order of their own experiences, because this mattered to them (Dor 2015: 155-156).

But motivation works differently. As described by Merleau-Ponty (2012: 51) in his discussion of perception, it is "a sort of operative reason" active in a given field which becomes tangible only after the fact. This "fluid" concept (Merleau-Ponty 2012: 51) may be illustrated by illusions, like the rabbit-duck figure. We become aware that the picture is ambiguous after the gestalt flip; only then can we realize that the figure offers sufficient motives for both readings. Generally speaking, human experience offers an infinite number of motives which may be "taken up" in perception. This fluidity of experience ("operative reason") is revealed by illusions and also in unprecedented situations, for instance, on board of a spaceship with no gravity, where no directions are "privileged". A successful first expression (articulation) of experience works similarly: its aptness (le mot just) leads to the "right meaning", only in the light of which can the aptness ("operative reason") become tangible (cf. Merleau-Ponty 2012: 179ff.) I have argued elsewhere, for instance, that the original aptness of the name "cuckoo" is not motivated by the iconic relation between the sounds in question but rather by the word's expressiveness: its capacity to evoke the right meaning. Since many other onomatopoeias are not used as names, we may assume that it is the distinctiveness of the cuckoo's call (the fact that the bird is recognized primarily by the call) that motivates the original act of naming (Pawelec 2007: 207).

Dor, however, wants to treat iconicity as a set of abstract communicative rules discovered at some point by innovative individuals and adopted at large (or imposed) in some cases. As a result, I believe, he not only loses from view the importance of motivation in the process of articulation, but also - ironically, perhaps - he is more likely to disregard social factors contributing to the expressiveness of symbolic forms. For instance, iconicity in instructions (cookbooks, travel guides) reflects the intended order of doing or viewing but it seems "natural" in such cases because telling is used 
to direct appropriate performance. Iconic expressiveness of this kind is embedded in social frameworks not by fiat but by pragmatic aptness.

I have given more attention to the issue of motivation (a foundational one in phenomenological accounts) because it highlights a more general problem with Dor's instrumental view of language. Dor (2015: 1) assumes from the start that language is "essentially a communication technology", rather than a social institution like family or a cognitive capacity like vision; it is a technology because "each of its components has to be built before it can be used" (Dor 2015: 25). To quote Dor on iconicity in language again: it is there because "some innovative individuals realized [...] that communication would become more effective [...]" (Dor 2015: 155). The same goes for pointing - the crucial communicative technology before language, according to Dor. Contrary to standard accounts which underline that pointing is effective only against "an already established, intersubjective common ground", Dor (2015:36) claims that pointing "serves us when common ground is required, not when it is already there". Pointing "allows us to systematically mutually identify elements of our experiences $[\ldots]$ and thus work together to reduce the experiential gap between us" (Dor 2015: 37). This neglects (again, ironically) the necessary social transformations which made pointing possible in our evolutionary history: the move beyond directing others with gestures (this is how pointing is understood by dogs and used by enculturated apes) towards directing others' attention. The latter activity requires a much greater commonality, possibly based in ritual sharing (cf. Taylor 2016: 62-3, quoting Tomasello 2003: 290). Consequently, the category Dor calls "presentational communication" (which includes both animal and human "gesturing") may perhaps be used for didactic purposes but it does not reflect a commonality of behaviour. To conclude, informative uses of pointing and language are rooted in more basic social activities (and transformations).

This is actually the claim developed by the phenomenological tradition (and Taylor). From this perspective, language is primarily a social institution (cf. also Malinowski's notion of "phatic communion") which, to quote Gadamer (2004: 420), "has its being in its revealing"; thus, it is also like a new cognitive capacity - a "new sense" (there is an echo of this view in the last paragraph of Metaphors we live by, cf. Lakoff, Johnson 1980: 237). Dor's initial distinction quoted above (language as "essentially a communication technology") serves again, I believe, didactic purposes.

In spite of the apparent clash of agendas ("language as a tool of instruction" for Dor vs. "language as a new way of communal being" for Taylor) I would like to propose that they share enough common ground to hope that both books (along with other attempts) will change the present cognitive climate in language study.

\section{References}

Dor D. 2015. The instruction of imagination: Language as a social communication technology. Oxford.

Everett D. 2012. Language: The cultural tool. New York.

Gadamer H.-G. 2004 [1975]. Truth and method. London, New York. 
Harris R., Wolf G. (eds.). 1998. Integrational linguistics: A first reader. Oxford.

Lakoff G., Johnson M. 1980. Metaphors we live by. Chicago.

Leezenberg M. 2001. Contexts of metaphor. Amsterdam.

Malinowski B. 1923. The problem of meaning in primitive language. - Ogden C.K., Richards I.A. (eds.). The meaning of meaning. London: 296-336.

McNeill D. 2005. Gesture and thought. Chicago, London.

Merleau-Ponty M. 2012 [1945]. Phenomenology of perception. London, New York.

Pawelec A. 2007. A note on iconicity and motivation of expression. - Research in Language 5: 205-212.

Pawelec A. 2009. The Romantic theory of language and metaphor. - Garbowski C. et al. (eds.). Charles Taylor's vision of modernity. Reconstructions and interpretations. Newcastle upon Tyne: 194-204.

Pinker S. 1994. The language instinct. The new science of language and mind. London.

Reddy M.J. 1979. The conduit metaphor. - Ortony A. (ed.). Metaphor and thought. Cambridge: $284-324$.

Saussure F. de. 1959 [1916]. Course in general linguistics. New York.

Spronck S. 2016a. (rev.). Dor 2015. [lirias.kuleuven.be/handle/123456789/543181? mode=full].

Spronck S. 2016b. The instruction of imagination: Language as a social communication technology. - Australian Journal of Linguistics. [http://dx.doi.org/10.1080/07268602. 2016.1255121].

Stalmaszczyk P. 2016. (rev.). Taylor 2016. [marxandphilosophy.org.uk/reviewofbooks/ reviews/2016/2501].

Taylor C. 1985. Human agency and language. Philosophical papers 1. Cambridge.

Taylor C. 1995. Philosophical arguments. Cambridge (Mass.).

Taylor C. 2006. An issue about language. - Jourdan C., Tuite K. (eds.). Language, culture, and society. Cambridge: $16-46$.

Taylor C. 2011. Dilemmas and connections. Cambridge (Mass.).

Taylor C. 2016. The language animal. The full shape of the human linguistic capacity. Cambridge (Mass.), London.

Tomasello M. 2003. Constructing a language. A usage-based theory of language acquisition. Cambridge (Mass.). London.

Vygotsky L.S. 1962 [1934]. Thought and language. Cambridge (Mass.).

Werner H., Kaplan B. 1963. Symbol formation. New York.

Wittgenstein L. 1978 [1953]. Philosophical investigations. Oxford. 